\title{
Therapeutic Targeting of the Colorectal Tumor Stroma
}

Wolf H Fridman ${ }^{1}$, Ian Miller ${ }^{2}$, Catherine Sautès-Fridman ${ }^{1}$ and Annette T. Byrne ${ }^{2}$

${ }^{1-}$ Centre de Recherche des Cordeliers, INSERM, Sorbonne Université, USPC, Université de Paris, Inflammation, complement and cancer team,

F-75006 Paris, France. ${ }^{2}$ Dept. of Physiology and Medical Physics, Royal College of Surgeons in Ireland, Dublin 2, Ireland.

Funding

WHF, CSF and ATB receive funding from the European Union's Horizon 2020 Research and Innovation Programme under Grant Agreement No. 754923 “COLOSSUS” A.T.B. is further supported by Science Foundation Ireland under grant 13/CDA/2183 'COLOFORETELL' and by the Health Research Board under grant ILP-POR-2019-066

WHF, CSF receive funding from INSERM, Université de Paris, Sorbonne University, CARPEM T8, the Labex Immuno-Oncology Excellence Program, Institut du Cancer (INCa), HTE Plan Cancer (C1608DS), and the Cartes d'Identité des Tumeurs (CIT) Program from the Ligue Nationale Contre le Cancer

Acknowledegments 


\begin{abstract}
Colorectal tumors have been classified based on histologic factors, genetic factors, and consensus molecular subtypes, which all affect the tumor microenvironment (TME). Elements of the TME serve as therapeutic targets and might be used as prognostic factors. For example, immune checkpoint inhibitors are used to treat tumors with microsatellite instability, and anti-angiogenic agents may be used in combination with other drugs to slow or inhibit tumor growth. We review the features of the colorectal tumor stroma that associate with outcomes of patients and discuss potential therapeutic agents that target these features.
\end{abstract}

Keywords : CRC, MSI, microenvironment, matrix 
In patients with colorectal cancer (CRC), distinct molecular features of tumor cells alter the tumor's microenvironment (TME) to affect its growth and metastasis ${ }^{1,2}$. The TME contains an extracellular matrix (ECM) made of collagen fibers, layers of fibroblasts, blood and lymphatic vessels, nerves, and cells of hematopoietic origin ${ }^{1,3}$. Among the hematopoietic cells, lymphocytes and myeloid cells influence tumor development directly or via the mediators they produce. In general, colorectal tumors are most heavily infiltrated by macrophages, followed by $\mathrm{T}$ and $\mathrm{B}$ cells ${ }^{4}$. These immune cells interact with tumor cells and other stromal cells. The tumor stroma determines interactions among lymphocytes, myeloid cells, fibroblasts, endothelial cells, lymphatics, and tumor cells. Different components of the TME can affect clinical outcome.

There are different types of colorectal tumors, which each have different features of the TME. For example, colorectal tumors with microsatellite instability (MSI) have defects in DNA repair enzymes and are highly infiltrated by lymphocytes ${ }^{5}$. Most colorectal tumors, however, have low levels of infiltration by lymphocytes and varying densities of myeloid cells, endothelial and lymphatic cells, and fibroblasts. ${ }^{6,7}$. However, a subgroup of colorectal tumors is characterized by medium levels of infiltration by lymphocytes and high densities of endothelial cells and fibroblasts. This group, called mesenchymal colorectal tumors, has high metastatic potential and patients have poor prognoses ${ }^{8}$. These highly aggressive tumors have a complex stroma. Colorectal tumors with specific mutations in RAS are an intriguing subgroup that are resistant to inhibitors of epidermal growth factor receptor (EGFR) ${ }^{9-11}$. The efficacy of antibodies against EGFR might depend on their interactions with immune cells ${ }^{12}$, so learning more about the TME can lead to strategies to improve therapies. We review the major components of the colorectal tumor stroma and their potential for therapeutic targeting. We discuss new therapeutic strategies to alter the colorectal tumor stroma. 


\section{The Microenvironment in Tumorigenesis}

CRC develops via a multistep process that involves the sequential accumulation of mutations in colonic epithelial cells ${ }^{13}$. However, colorectal tumor development also involves interactions between these cancer cells and their microenvironment. This environment includes immune cells, neurons, fibroblasts, blood vessels, and lymph tissues (see Table 1).

\section{Inflammation}

Inflammatory diseases of the colon, such as ulcerative colitis and Crohn's disease, ${ }^{14,15,16}$ promote tumorigenesis via alterations to immune cells, blood vessels, and the colon mucosa ${ }^{17}$. Mice given dextran sulfate sodium (to induce colitis) followed by azoxymethane (an mutagenic alkylating agent) develop colitis-associated cancer ${ }^{17}$ similar to that in patients. Studies of these mice have indicated the roles of toll-like receptors and inflammatory cytokines, as well as colonic microbiome, in the generation of CRC ${ }^{18}$.

Patients with inflammatory bowel diseases have a significant increase in risk of CRC, due to the neoplastic effects of chronic intestinal inflammation. Chronic inflammation can lead to chromosome abnormalities, MSI, and epigenetic changes such as DNA hypermethylation. Inflammation also involves changes in expression of cytokines, chemokines, cyclooxygenase enzymes, and transcription factors, as well as in production of reactive oxygen species and the composition of the intestinal microbiome. Loss of p53 from colorectal tumors is associated with increased intestinal permeability, causing formation of an NF- $\kappa \mathrm{B}$-dependent inflammatory microenvironment and the induction of epithelialmesenchymal transition $(\mathrm{EMT})^{19}$.

T cells, myeloid cells, and blood and lymphatic vessels are found in the center of the tumor and its invasive margin. Natural killer (NK) cells are often anergic ${ }^{35}$ and relegated to the invasive margin. B cells are primarily incorporated in lymphoid aggregates, called tertiary 
lymphoid structures (TLS), within the invasive $\operatorname{margin}^{36}$. Macrophages are the most abundant hematopoietic cells in the colorectal TME and are distributed between the tumor center and the invasive margin, whereas T-helper 17 (Th17) cells, mast cells, and neutrophils are mostly present in the invasive margin ${ }^{37}$. Although most mature dendritic cells are present in TLS, which are in close contact with $\mathrm{T}$ cells, immature dendric cells are also detected throughout the center of the tumor. Intestinal microbes can also induce production of inflammatory cytokines such as interleukin 17 (IL17) ${ }^{20}$. Increased levels of IL17 in colorectal tumors have been associated with shorter survival times of patients ${ }^{21}$.

\section{Neural cells}

The colon contains millions of neurons, which interact with lymphoid tissue in the intestine. Neural cells located in the tumor stroma facilitate migration of metastatic cells - neural invasion of a tumor is an early sign of its invasiveness ${ }^{24}$. In prostate tumors, neurogenesis is initiated from neural progenitors from the central nervous system and newly formed nerve fibers sustain tumor initiation and progression ${ }^{25}$. Signaling by the chemokine CXCL13 via its receptor CXCR5 mediates interactions between neural cells, cancer cells, and the TME. High levels of CXCL13 and CXCR5 correlate with neural invasion of the TME and shorter survival times for patients with advanced $\mathrm{CRC}^{26}$. CXCL13 can induce the migration of CXCR5-positive neural precursor cells across the endothelium in humans ${ }^{27}$. Moreover, CXCR5 expression is required for differentiation of neural precursor cells into neurons in adult zebrafish ${ }^{28}$. CXCR5 is expressed by many colon cancer cell lines ${ }^{29}$, by B cells, and a subset of $\mathrm{T}$ cells in the $\mathrm{TME}^{30,31}$. More studies are needed to investigate interactions among nerves, immune cells, and tumor cells.

\section{Fibroblasts}


Fibroblasts are major constituents of the invasive margin, where they provide a physical barrier and remodel the $\mathrm{ECM}^{3}$. The densities, the location, and the functional orientation of these different cell types, as well as the presence or absence of TLS are prognostic factors for patients with $\mathrm{CRC}^{1}$.

Cancer-associated fibroblasts (CAFs) originate from several cell types, including epithelial and endothelial cells, local fibroblasts, and mesenchymal cells from the bone marrow (reviewed in ref 3). CAFs are a heterogeneous population of cells that undergo epigenetic modifications during cancer development. CAFs that resemble quiescent fibroblasts facilitate tissue regeneration during the early steps of carcinogenesis. Activation of CAFs during tumor progression is regulated by factors including transforming growth factor beta (TGFB), platelet derived growth factor (PDGF), hedgehog, bone morphogenic protein, IL1, IL6, TNF, and reactive oxygen species $^{32}$. Activated CAFs acquire a highly contractile and proliferative phenotype and produce ECM proteins (collagen, fibronectin, proteoglycan, periostin and tenascin C). They support tumor growth indirectly, via collagen fibers that form the stiff ECM that prevents the entry of lymphocytes and drugs in the tumor center, and through the production of immunosuppressive, angiogenic, and inflammatory factors (Table 1). For a review on CAFs in colorectal tumor development, see Kabayashi et $\mathrm{al}^{32}$. Better markers are needed to detect CAF subtypes and determine their prognostic value.

\section{Vasculature}

Blood and lymphatic vessels infiltrate the tumor core and the invasive margin ${ }^{24}$. Endothelial cells regulate angiogenesis, but pericytes, (peri-endothelial smooth muscle cells that express $\alpha$ smooth muscle actin) support endothelial cell function and are required for development of a tumor vascular network ${ }^{33}$ (Table 1). Eberhard et al have shown that the percentage of 
endothelial cells covered with pericytes varies among tumor types (such as 65\% pericyte coverage in colorectal tumors vs $13 \%$ in glioblastomas) ${ }^{34}$.

Endothelial cells within the tumor form new blood vessels. However, these cells are highly proliferative and prone to apoptosis, unlike the endothelium of normal tissue ${ }^{120}$. Tumor vessels are disorganized, tortuous, and dysfunctional, whereas the normal vasculature has a hierarchical branching pattern of arteries, veins, and capillaries $\underline{\underline{19}}$. In the normal vasculature, expression of VEGF and angiogenic factors is tightly regulated, and levels decrease rapidly upon new vessel formation. However, during tumor growth, the balance in expression of angiogenic vs anti-angiogenic factors is shifted toward continuous neoangiogenesis ${ }^{121}$.

VEGF signaling is complex ${ }^{122}$, with VEGF gene expression upregulated by hypoxia, through activation of the HIF1 transcription factor, and by integrin or oncogene signaling ${ }^{123}$ (such as EGFR signaling). VEGF receptors are expressed not only by vascular endothelial cells but also by other cells, including macrophages and monocytes ${ }^{125}$, providing evidence for a role in immune modulation, angiogenesis and metastatic progression . Other signaling pathways interact with VEGF signaling, such as the angiogenin, TIE1, and Notch signaling pathways $^{126}$.

In a meta-analysis, Wang et al associated higher levels of VEGF with tumor metastasis to lymph nodes and blood vessels. ${ }^{127}$ Tumor level of VEGF might therefore be a prognostic marker for patients with CRC. Similarly, the incidence of metastases was higher in patients whose tumors expressed high levels of VEGF, which might be used in prognosis. Sustained levels of angiogenesis, revealed by the tumor endothelial cell signature, correlate with reduced patient survival times $\underline{51}$. Mohamed et al showed that patients whose colorectal tumors expressed high levels of VEGF, CD105 (endoglin; glycoprotein involved in TGF receptor complex), and CD31 (endothelial cell marker) had poor outcomes ${ }^{128}$. 


\section{Lymphangiogenesis}

Lymphatic vessels maintain fluid balance by draining interstitial fluid to regional lymph nodes. During metastasis, they provide a pathway for tumor cell dissemination. ${ }^{145,146}$ Lymphangiogenesis (the process where new lymphatic vessels are formed) occurs in and around tumors ${ }^{147}$. In colorectal tumors, there is a correlation between lymphatic microvessel density and risk of metastasis ${ }^{146}$.

Lymphangiogenesis is mediated by VEGFC and VEGFD ${ }^{148},{ }^{149,150}$. These factors bind to the receptor tyrosine kinase VEGFR3 expressed on lymphatic cells resulting in neolymphangiogenesis. Other factors such as HGF, PGDF, FGF2, IGF1, and IGF2 stimulate lymph vessel outgrowth ${ }^{148}$. Lymphangiogenesis is inhibited by TGFB1, which also regulates tumor development. In mice undergoing wound repair, addition of exogenous TGFB1 inhibited assembly of lymphatic vessels, reduced lymphatic endothelial cell proliferation, and inhibited lymphatic endothelial cell migration ${ }^{151}$.

\section{Tumor Cell Mutations and the TME}

Among patients with colorectal tumors with high levels of MSI, $16 \%$ were found to have Lynch syndrome ${ }^{40}$ — an inherited cancer syndrome caused by mutations in genes that encode DNA repair enzymes. These tumors have a high mutation burden and are infiltrated by a large number of lymphocytes ${ }^{38}$. Patients with these tumors have better outcomes than tumors without MSI, because of the adaptive immune response mediated by $\mathrm{T}$ cells that recognize the tumor neo-antigens created by the high-frequency mutations ${ }^{41}$. This immune response slows tumor growth and metastasis. Microsatellite-stable (MSS) tumors ${ }^{4,88}$, alternatively, have less infiltration of by lymphocytes. MSS tumors often have mutations in oncogenes such as $A P C, K R A S, T P 53$, or PIK3CA. These tumors can acquire additional mutations due to 
mutations in the DNA polymerase epsilon gene $(P O L E)^{43,44}$, which increases their activation of the anti-tumor immune response. Patients with these colorectal tumors have longer than average survival times ${ }^{45}$.

COLOSSUS (www.colossusproject.eu), a multi-disciplinary European Commissionfunded research network, is studying the development, stromal composition, and resistance mechanisms of colorectal tumors with RAS mutations. Tumors with RAS mutations are resistant to treatment with antibodies against $\mathrm{EGFR}^{9,10}$. Most mutations in KRAS occur in exon 2 (codon 12 and 3$)^{46}$; patients whose tumors have these mutations do not benefit from anti-EGFR therapy ${ }^{47}$, with the possible exception of patients with tumors with the KRAS.G13D mutation ${ }^{48,49}$. Other mutations in RAS (KRAS exons 3 and 4; NRAS exons 2, 3 , and 4) are also associated with poor response to anti-EGFR treatments ${ }^{50}$. BRAF is downstream of Ras in the EGFR signaling pathway and the BRAF V600E mutation is associated with resistance to EGFR therapy ${ }^{51}$. It is not clear why antibodies that bind and activate effector cells in the TME do not induce tumor cell killing by macrophages or NK cells. Tumors with RAS mutations might become resistant to NK cell killing downregulate the anti-tumor immune response by unknown mechanisms ${ }^{52,53}$. For a review of tumor mechanisms of resistance to EGFR inhibitors, see ref ${ }^{54}$.

\section{Molecular Classifications and the TME}

Transcriptome-based classifications of colorectal tumors have been proposed ${ }^{55-62}$. A Consensus Molecular Classification system ${ }^{63}$ has been developed an provides a useful tool to classify tumors and study their corresponding TMEs. There are 4 consensus molecular subtypes (CMSs). CMS1 (14\% of colorectal tumors) contains most, although not all, hypermutated MSI tumors with BRAF mutations and the high $\mathrm{CpG}$ island methylator phenotype, resulting in the methylation and subsequent inhibition of transcription of the 
mismatch repair gene $\mathrm{MLH}^{64}$ and few somatic copy number alterations. CMS2 (37\% of colorectal tumors) is characterized by mutations in $A P C$ and activation of WNT and MYC. CMS3 tumors (13\% of colorectal tumors) have metabolic deregulation and have many tumor cells with KRAS mutations. CMS4 tumors (23\% of colorectal tumors) upregulate genes involved in the EMT, TGFB signaling, angiogenesis, and ECM remodeling ${ }^{63}$.

An in-depth analysis of the composition and activation states of the stromal components associated with each $\mathrm{CMS}^{42}$ revealed that CMS1 tumors had a high expression of genes that regulate T-cell trafficking and activation as well as differentiation of Th1 and cytotoxic T cells, and high expression of CXCL13. CMS1 tumors have a high density of infiltrating $\mathrm{CD}^{+} \mathrm{T}^{+}$cells ${ }^{42}$. Patients with CMS1 tumors have longer survival times than patients with other CMSs, supporting the concept that hypermutated tumors of this subtype induce specific T- and B-cell responses that control tumor dissemination and metastasis. However, CMS1 tumors express high levels of immune check point molecules such as PD1 and cytotoxic T-lymphocyte associated protein 4 (CTLA4).

The TME of CMS2 tumors is characterized by low numbers of lymphocytes, macrophages endothelial, and fibroblastic cells. CMS3 tumors are heterogeneous but are characterized by low levels of immune cell infiltration ${ }^{42}$. CMS4 tumors are the most aggressive subtype with the worst outcomes. CMS4 tumors express immune checkpoint molecules, and are highly infiltrated by macrophages, myeloid-derived suppressor cells (MDSCs), MDSCs, and fibroblasts. CMS4 tumors express high levels of the chemokines CCL2 and CXCL12, which recruit myeloid cells and promote neural migration. CMS4 tumors have low levels of CXCL13, which regulates formation of TLS, indicating a disorganized anti-tumor immune response and lack of $\mathrm{T}$ and $\mathrm{B}$ cells that recognize tumor antigens $^{31}$. CMS4 tumors are characterized by an inflammatory gene expression signature, with high expression of genes encoding components of complement system. They also 
express high levels of genes that encode TGFB and LGALS1, which are immunesuppressive, and the angiogenic factors VEGF and PDGFC ${ }^{42,63,65}$. The abundance of fibroblasts found in CMS4 tumors correlates with myeloid and endothelial cell abundance, indicating that fibroblasts might promote angiogenesis and recruitment of inflammatory cells 42.

In the stroma of CMS4 tumors, fibroblasts express high levels of VEGFB, VEGFC, PDGFC, LGALS1, CXCL12, PTGS1, and TGFB to promote angiogenesis, lymphangiogenesis, and immune suppression. Endothelial cells in these tumors express high levels of CCL2, PDGFB, and TGFB1 and TGFB2. Finally, monocytes in CMS4 tumors express complement components (C1QA, C1QC, C3, C3AR1, and C5AR1) and chemokines that attract macrophages (CCL19 and CCL23). These cell populations contribute to progression of CMS4 colorectal tumors by promoting inflammation, angiogenesis, and immunosuppression.

Although practical, the CMS classification system faces many hurdles. Integration of cancer cell and stromal gene expression signatures depends on the purity of the tumor sample analyzed. CMS1 and CMS4 are over-represented in samples containing a large proportion of stromal tissue ${ }^{66}$. In addition, the CMS system is based on average characteristics, and does not take into account tumor heterogeneity ${ }^{66}$. The cancer cell intrinsic subtype classification system, established from tumor patient-derived xenografts ${ }^{67}$ appears to be more robust, but does not integrate the TME. Other immune classification systems overlap imperfectly with the CMS system, so further molecular classifications are needed to guide TME targeted therapies.

\section{Chromosome Instability and the TME}


There have been many studies of gene copy number changes in colorectal tumors; ${ }^{68}$ these have also been used to create a CRC classification system, based on chromosome instability. ${ }^{69}$. Copy number load was initially studied as a potential biomarker of response to bevacizumab in patients with metastatic CRC. Specifically, 472 primary tumors that metastasized were classified into 3 subgroups (clusters 1-3), each characterized by different degrees of chromosome instability. Tumors with increasing cluster numbers (cluster 1-3) had an increasing number of chromosomal breakpoints and a higher proportion of the genome with copy number alterations (CNAs).

Researchers used publicly available TCGA datasets to correlate clusters of CNAs with $\mathrm{CMSs}^{77-84}$. Gene set enrichment analysis of 50 cancer-associated pathways applied to differentially expressed genes between clusters of CNAs revealed that cluster 1 tumors were characterized by a strong immune-activated microenvironment, whereas cluster 2 and 3 tumors were characterized by angiogenesis, EMT, and inflammatory response pathways. Tumors from cluster 1 overlapped with CMS1 or CMS3 tumors, whereas cluster 2 and 3 tumors overlapped with CMS2 or CMS4 tumors, respectively.

\section{Colon Side and the TME}

Left-sided and right-sided colon tumors have distinct histologic and molecular characteristics. Right-side colon tumors arise from the ascending colon and proximal two thirds of the transverse colon whereas left-side colon tumors arise from the descending or sigmoid colon, and distal third of the transverse colon ${ }^{70}$. Right-side stage III or IV colon tumors are generally associated with short survival times. These tumors are more commonly MSI, have BRAF mutations, and are hypermutators ${ }^{71}$, compared with left-side tumors, which have chromosome instability. High numbers of PD1+ $\mathrm{CD} 8^{+} \mathrm{T}$ cells, $\mathrm{FOXP}^{+} \mathrm{T}$ cells, $\mathrm{CD} 20^{+} \mathrm{B}$ cells, and $\mathrm{CD}_{138}{ }^{+} \mathrm{IGKC}^{+}$plasma cells in tumor tissues has been associated with increased OS survival 
times of patients with right-side colon tumors ${ }^{72}$. Differences in immune cell features of the right vs left colon might account for the different outcomes of patients with right-side vs leftside colon tumors ${ }^{70}$.

The human colon contains complex and diverse microbial colonies of approximately $10^{13}$ to $10^{14}$ bacteria, ${ }^{70}$ with colony numbers increasing from right to left. Therefore, the left colon, with the highest concentration of microbes, has a more tolerant immune environment. Tumors that develop in the right colon face a more active immune environment than tumors in the left colon, ${ }^{70}$ and are infiltrated by higher numbers of lymphocytes. Tumors in the left colon have a higher level of immune-suppressive cells than tumors of the right colon ${ }^{73}$.

\section{Clinical Effects of TME Composition}

Primary tumors with no perineural infiltration and no vascular or lymphatic invasion have a higher density of memory $\mathrm{T}$ cells than tumors with early signs of metastasis ${ }^{74}$. High densities of memory and effector $\mathrm{T}$ cells, particularly $\mathrm{CD} 8^{+} \mathrm{T}$ cells, in the center and the invasive margins of tumors correlated with longer progression-free survival (PFS) and overall survival (OS) times of patients ${ }^{75}$. Analysis of hepatic ${ }^{76}$ and lung ${ }^{77}$ metastases also associated higher densities of $\mathrm{CD}^{+} \mathrm{T}$ cell with better outcome. Although infiltration by $\mathrm{CD} 8^{+} \mathrm{T}$ cells appears to have positive effects for tumors of all stages, more advanced tumors (stages III and IV) have lower densities of these cells than early-stage tumors ${ }^{78}$. A reduced adaptive immune response might therefore promote tumor progression ${ }^{78,79}$.

Analyses of primary tumors and metastases from the same patients provided evidence for immune selection of malignant cells ${ }^{80}$. This mechanism is prevalent in MSI tumor cells, which often lose membrane HLA molecules, ${ }^{81-83}$ so they escape T-cell cytotoxicity but not NK cell cytotoxicity. This reduces their metastatic potential ${ }^{52}$. Analyses of tumor transcriptomes revealed that high expression of genes that regulate $\mathrm{T}$-cell chemotaxis 
(CXCL9, CXCL10, CXCL11), T- and NK-cell activation (IL15), and Th1 cell development (IFNG) associated with longer survival times of patients ${ }^{1,84}$. Tumors with mutations resulting in loss of expression of IL15 $5^{85}$ or CXCL13 ${ }^{4}$, which attracts B cells and is involved in TLS formation, resulted in shorter survival times of patients. Infiltration of colorectal tumors by Th2 $2^{21}$ and Th1 $17^{4}$ cells has been associated with shorter survival times, whereas T follicular helper cells were associated with longer survival times, as were high levels of tumor infiltration by B cells ${ }^{2,4,86}$ and the presence of $\mathrm{TLS}^{2,87}$. The overall positive effects of high Tcell density in colorectal tumors led to the establishment of an Immunoscore, based on quantification of $\mathrm{CD}^{+}$and $\mathrm{CD} 8^{+} \mathrm{T}$ cells in the center and the invasive margin, which was associated with increased survival times of patients with MSI or microsatellite stable (MSS) tumors $^{4,88}$.

CRC tissues are enriched in commensal bacteria such as Bacteroides fragilis and Escherichia $\operatorname{coli}^{89}$. These bacteria produce stimuli that upregulate expression of genes encoding chemokines that attract $\mathrm{T}$ cells to tumors, associated with longer survival times of patients. The abundance of these bacteria in colorectal tumors also correlates with expression of chemokines that recruit $\mathrm{T}_{\text {cells }}{ }^{30}$. The mechanisms of bacterial species such as Fusobacterium nucleatum, which are associated with lower densities of T cells ${ }^{90}$, lymph node metastasis ${ }^{89}$, and poor outcomes, ${ }^{91}$ require further study ${ }^{92}$.

Tumor-associated macrophages (TAMs) form a heterogeneous and versatile population of cells, most of which are located in the stroma along the invasive front. The presence of $\mathrm{CD} 68^{+}$macrophages has been associated with increased survival times of patients with $\mathrm{CRC}^{2}$ whereas $\mathrm{CD}_{163^{+}}$macrophages have a negative effect ${ }^{2,93}$. Whereas colorectal tumor cells express low levels of the immune checkpoint ligand CD274 molecule (also called PDL1), TAMs located in the invasive margin express high levels of PDL1 and are more abundant in MSI than MSS tumors, indicating a role in the CRC adaptive resistance 
phenomenon ${ }^{94}$. Neutrophils are also present in the TME and correlate with improved outcomes and response to 5 FU-based chemotherapy ${ }^{95}$. Macrophages and neutrophils might derive from the local differentiation of MDSCs, a heterogenous population of immature myeloid cells that lack robust cell surface markers for detection by immunohistochemistry. However, the prognostic value of MDSCs requires evaluation in large cohorts of patients. Mast cells are associated with poor outcomes in 1 study $^{96}$.

A gene expression pattern characteristic of fibroblasts associated with reduced survival time survival and decreases the positive effects of a cytotoxic cell signature ${ }^{86}$ This finding has been attributed mostly to the fact that CAFs produce immunosuppressive $\mathrm{TGFB}^{97,98}$ and VEGF, ${ }^{99}$ which impair immune responses even when lymphocytes are able to cross the fibroblastic barrier ${ }^{3}$.

\section{Immune-based Therapies}

CRC was once considered to be resistant to immunotherapy. This changed in 2015 , when the striking response of patients with metastatic MSI tumors to anti-PD-1 therapy ${ }^{100}$ has opened new avenues and raised questions about therapies to target the tumor stroma. These agents re-activate T-cell anti-tumor responses by blocking checkpoint molecules such as programmed cell death 1 (PDCD1, also called PD1) ${ }^{100}$. Immunotherapy for CRC has become the paradigm for all types of tumors with MSI, and for tumors with a high mutation burden ${ }^{101}$. Trials are underway to determine whether the combination of anti-PD1 and antiCTLA4 increases the response rate and survival times of patients with MSI tumors ${ }^{102,103}$ (see Table 2).

MSI tumors have all characteristics required to respond to immune checkpoint inhibitors ${ }^{104}$, are surrounded by PD1+CD8+ T cells, and express high levels of PDL1 ${ }^{94}$. MSI tumors account for only $3 \%-5 \%$ of all metastatic colorectal tumors ${ }^{23}$. However, 
extension of immune checkpoint inhibitor therapy to treatment for primary colorectal tumors might increase the number of patients who benefit from these therapies. Computational strategies (deep residual learning) diminish the price to identify tumors with MSI based on histologic features that might result in immune checkpoint inhibitor therapy for a larger number of patients with $\mathrm{CRC}^{105}$.

Interestingly, the efficacy of PD1 inhibitors against MSI tumors raises questions that, if answered, might reveal new treatment options for MSS tumors. For example, due to immune-cell selection, many MSI tumors express few or no HLA molecules, which are required for antigen presentation to $\mathrm{CD} 8^{+} \mathrm{T}$ cells ${ }^{38}$. This might explain the growth of primary MSI tumors despite their infiltration by T cells. However, HLA defects are rare in liver metastases, in contrast to metastases in other organs ${ }^{81}$, which could account for the response of patients with metastatic CRC, which usually spreads to the liver, to PD1 inhibitors ${ }^{100}$. Studies of responses in patients with primary MSI tumors that have lost HLA expression ${ }^{82}$ should help answer this important question and provide additional information about mechanisms of immune checkpoint inhibitor therapy. In MSI tumors that have lost HLA expression, responses to PD1 inhibitors could resemble the sensitivity of Hodgkin disease, which despite a loss of HLA expression responds to PD1 inhibitors. ${ }^{106}$ Other T-cell subsets or NK cells might act as effectors.

It is also important to learn why MSS colorectal tumors that are highly infiltrated by T cells do not respond to immune checkpoint inhibitors. It has been proposed that the Immunoscore (the density of $\mathrm{CD} 3^{+}$and $\mathrm{CD} 8^{+} \mathrm{T}$ cells) more accurately predicts survival times of patients with CRC than MSI ${ }^{107}$. In MSS tumors, $\mathrm{CD}^{+} \mathrm{T}$ cells might control tumor growth but still cannot promote tumor regression — other elements of the TME might continue to support tumor development. CMS4 tumors are characterized by high levels of myeloid cell infiltration, high levels of angiogenesis, and fibroblastic contents. ${ }^{42}$ These tumors might be a 
paradigmatic stroma-rich colorectal tumor sub-class that contains many different cell types and would be a good candidate for testing TME-targeted therapies. Studies are needed to determine whether immune checkpoint inhibitors can be used in combination with other strategies for treatment of MSS tumors. This question is further under consideration by the COLOSSUS CRC research network.

Most TAMs have an M2 phenotype, produce complement components, and have inflammatory and angiogenic activities ${ }^{108}$ such as production of $\mathrm{VEGF}^{109}$ and immunosuppressive cytokines (IL10) cytokines, ${ }^{110}$ resulting in T-cell exhaustion ${ }^{111}$ and angiogenesis $^{112}$. Therefore, the combination of anti-angiogenic and immune checkpoint inhibitor therapy might result in reactivation of the anti-tumor immune response ${ }^{112}$. This combination is currently being tested in patients with MSI colorectal tumors (TECENTRIC, NCT02982694). Agents that block colony stimulating factor 1 receptor, or the CCL2 receptors CCR2 and CCR5, which are expressed by macrophages and MDSCs and induce macrophage repolarization, ${ }^{113}$ are being tested in MSS in combination with anti-PD1 and anti-PDL1 in patients with advanced CRC (NCT02713529 with AMG 820, and MARACON, NCT03184870).

Neutralization of inflammatory complement components is a new strategy for treatment of $\mathrm{CRC}^{108}$. Agents that block C5aR reduced tumor growth in mice, alone ${ }^{6}$ or in combination with a checkpoint inhibitor. ${ }^{29,109,110}$ A phase 1 study is underway to test the combination of a C5aR inhibitor and anti-PDL1 in patients (STELLAR-001, NCT03665129 (see Table 2). Agents that target different steps of the complement cascade might be adapted for cancer therapy ${ }^{112}$.

Fibroblasts produce TGFB and VEGF and mechanically prevent entry of therapeutic cells and agents into the tumor core ${ }^{3}$. It is a challenge to target fibroblasts therapeutically, given their heterogeneity, plasticity, and the role of ECM in maintenance of tissue stiffness. 
Of the immune-suppressive cytokines present in CMS4 tumors, TGFB is a challenge to target, given its multiple functions ${ }^{114}$. It may be similarly challenging to target IL10, due to its dual effects on the immune response ${ }^{115}$.

Indoleamine deoxygenase (IDO) is expressed by mesenchymal cells, myeloid dendritic cells, T-regulatory cells, and tumor cells. Trials of the IDO inhibitor, epadadostat, in combination with anti-PD1 blockade (ECHO-204, NCT02327078) are underway in patients with CRC. Oncolytic viruses replicate specifically in tumor cells and promote tumor infiltration by lymphocytes and induction of specific anti-tumor immune responses. These might be used to increase the response of MSS colorectal tumors to anti-PD1 therapy (NCT02963831 with ONCOS102). Tumor development results in epigenetic alterations that reduce antigen presentation and responses of T cells to tumor cells, allowing tumors to evade immune surveillance. Demethylating agents, which increase expression of genes including HLA genes, might increase antigen presentation ${ }^{116}$. These types of agents reduced tumor growth in mice and are being tested in combination with immune checkpoint inhibitors in patients with melanomas (Di Giacomo et al, Clin Cancer Res, in press). The histone deacetylase inhibitor entinostat is being tested in combination with anti-PD1 in patients with MSS colorectal tumors (NCT02437136).

Chemotherapies that include oxaliplatin have been reported increase immune cell cytotoxicity toward cancer cells and activation of the adaptive immune response ${ }^{117}$. Also, oncolytic viruses not only induce immune-cell killing of tumor cells, but also remodel the $\mathrm{TME}^{118}$. Inhibitors of beta-catenin or PAX4 might increase tumor infiltration by immune cells, and strategies are being developed to increase the immune response against MSS tumors (see Figure 3).

Other ways to increase the anti-tumor immune response would be to deliver T cells directly to the tumor core, using chemokines such as CXCL9 and CXCL10. It might be 
possible to increase interaction of tumor cells with immune cells using bi-specific antibodies, or by infusing effector T cells, tumor-infiltrating lymphocytes, or T cells with chimeric antigen receptors against tumor antigens (reviewed in ${ }^{103}$ ). Stem cell features of cancer cells have been associated with a suppressed immune response, higher intra-tumor heterogeneity, and reduced survival times of patients ${ }^{119}$. Inhibitors of stem cell markers such as CD133 or the polycomb group protein BMI1, or agents that induce tumor cell differentiation, might slow tumor growth or progression and reduce immunosuppression.

\section{Targeting the Tumor Vasculature}

In tumor tissues, the most common method to evaluate angiogenesis is to measure microvessel density (MVD), based on endothelial markers such as CD31, CD34, or endoglin. Nevertheless, studies have produced conflicting results on the prognostic value of MVD for patients with CRC. MVD was correlated with depth of invasion, metastasis to lymph nodes and distant sites, and tumor node metastasis stage; there was an inverse correlation between MVD and OS. ${ }^{127,129-131}$ In other studies, researchers found no correlation between MVD and PFS or OS ${ }^{132-135}$. Specifically, Prall et al ${ }^{134}$ reported that patients with tumors with high MVD had longer times of cancer-specific survival. The conflicting results might be due to differences in the methods used to determine MVD ${ }^{136}$. For markers that are detected by immunohistochemistry (CD31, CD34, and Von Willebrand factor) and size of area examined varied among studies. MVD has also been studied in patients treated with bevacizumab, a humanized monoclonal antibody that binds VEGF and inhibits its binding to its receptor. However Jubb et al $^{137}$ did not associate MVD with efficacy of bevacizumab in a post-hoc analysis of data from a trial of bevacizumab in addition to the standard of care (irinotecan, 5fluorouracil, and leucovorin) in patients with previously untreated metastatic $\mathrm{CRC}^{138}$. 
Angiogenesis inhibitors (antibodies or small molecules) are included in standard treatments for patients with CRC (for review, see ref ${ }^{139}$ ). Bevacizumab was the first angiogenesis inhibitor approved by the Food and Drug Administration for treatment of renal cancer ${ }^{140}$. It was subsequently approved as a first-line treatment agent for metastatic CRC, in combination with irinotecan, 5-fluorouracil, and leucovorin ${ }^{138}$. Inclusion of bevacizumab in this combination increased the mean OS time of patients from 15.6 months to 20.3 months. A retrospective analysis found no association between tumor mutations in $K R A S, B R A F$, or TP53 and survival time after bevacizumab therapy ${ }^{141}$. Bevacizumab alone is approved for first-line therapy for CRC, whereas other anti-angiogenic agents have only been approved for treatment of patients with tumor progression. The efficacy of bevacizumab as a second-line agent has been evaluated in patients whose metastatic CRC progressed after they were given the standard bevacizumab-containing regimen as their first-line therapy. ${ }^{142}$ This study found that that continued bevacizumab therapy prolonged OS (by 1.4 months) and PFS (by 1.6 months) (Table 2).

Drugs with a broader scope of inhibition have approved for treatment of CRC, such as aflibercept (VEGF Trap). Aflibercept is a high-affinity soluble decoy receptor for VEGF that was approved (in combination with FOLFIRI) for treatment of patients with metastatic CRC that progressed or is resistant to oxaliplatin-based therapies ${ }^{143}$. Ramucirumab is a monoclonal human IgG1 against the extracellular domain of VEGFR2 that prevents binding of VEGF AE, and consequently, VEGFR2 activation ${ }^{144}$. The small molecule angiogenesis inhibitor regorafenib has been approved for treatment of metastatic CRC. It is an orally administrated inhibitor of the tyrosine kinases VEGFR1-3, TIE2, FGFR1, PDGFR beta, KIT, and RET, RAF, RAF1, BRAF, and BRAFV600E. Regorafenib has been approved for salvage monotherapy in patients with refractory metastatic CRC, but it has a significant toxicity 
profile and questionable efficacy. Nevertheless, the drug is being tested in combination with FOLFIRINOX (NCT03828799) (See Table 3).

Li et al found an inverse correlation between levels of SMAD4 and TGFB1 with lymphatic microvessel density in a study of 147 patients colorectal tumors. ${ }^{152}$ Additionally, patients with SMAD4-positive tumors had significantly longer overall and tumor-free survival times than patients with SMAD4-negative tumors, indicating that TGFB1 signaling inhibits lymphatic outgrowth and reduces metastasis. Nevertheless, TGFB1 is a complex pleiotropic growth factor with paradoxical effects-it inhibits proliferation of normal epithelial cells and cells in early-stage tumors, but promotes proliferation of malignant and stroma cells in late-stage tumors. For a review of TGFB1 signaling in metastatic colorectal tumors and therapeutic strategies, see ref ${ }^{153}$

Agents designed to block lymphangiogenesis are being tested for their ability to prevent colorectal tumor metastasis. Unfortunately, lymphangiogenesis has proven a difficult process to specifically target in patients with $\mathrm{CRC}^{148}$. Sorafenib, an inhibitor of multiple tyrosine kinases, blocks VEGFR3, which regulates lymph vessel outgrowth. ${ }^{154}$ First-line treatment of patients with CRC with sorafenib in combination with FOLFOX did not increase patient survival time (RESPECT trial, NCT00865709) ${ }^{155}$. There is a large amount of redundancy in lymphangiogensis signaling, so if 1 pathway is blocked, another will compensate. No agent that interferes with lymphangiogenesis is being used in treatment of $\mathrm{CRC}^{148}$

\section{Biomarkers of Response to Treatment}

Resistance of tumor cells to drugs (initial or acquired during treatment) poses an constant challenge ${ }^{156}$, and strategies are needed to determine which tumors are most likely to respond to which therapies. Genomic ${ }^{50,69,157-163}$ and other classes of biomarkers of response have been 
proposed, ${ }^{164}$ but there are no markers that can be used to predict response to anti-angiogenic agents.

Chromosome instability was reported to be a biomarker of response to bevacizumab in patients with metastatic $\mathrm{CRC}^{69}$. Tumors with intermediate to high levels of chromosome instability (clusters 2 and 3) had better responses to chemotherapy with bevacizumab than to chemotherapy alone (prolonging PFS by 149 days for cluster 2 and 85 days for cluster 3 ). Colorectal tumors with low levels of chromosome instability (cluster 1), which include those with mutations in POLE and MSI, did not have an increased to chemotherapy that included bevacizumab, nor did metastatic colorectal tumors in phase 2 MoMa study (NCT02271464). A chromosome instability threshold in which $\geq 25 \%$ of chromosomal regions contained CNAs has been proposed for identification of tumors most likely to respond to bevacizumab. Patients whose tumors were above this threshold who received bevacizumab therapy had significantly longer times of PFS than those given the standard of care chemotherapy (REF132). This difference was not observed in when patients with tumors with high levels of chromosome instability were compared with patients with tumors with low levels of chromosome instability given chemotherapy alone. These require confirmation in a prospective trial, but CNA might be a biomarker of response to certain therapies.

Tebbutt et al investigated the association between CMS and response of patients with unresectable metastatic CRC to capecitabine; capecitabine and bevacizumab; and capecitabine, bevacizumab, and mitomycin (NCT00294359). ${ }^{165}$ Patients with CMS2 tumors (and possibly CMS3 tumors) given the combination of capecitabine and bevacizumab or capecitabine with bevacizumab and mitomycin had longer PFS than patients given capecitabine alone, but this association was not observed in patients with CMS1 or CMS4 tumors ${ }^{166}$. A retrospective analysis of patients with colorectal tumors without mutations in RAS treated with either mFOLFOX6 or FOLFIRI, combined with 
bevacizumab or cetuximab as first-line therapy, reported equal survival times (CALGB/SWOG 80405 trial). ${ }^{167}$ Interestingly, patients with CMS1 tumors had longer survival times after bevacizumab-based treatment than cetuximab-based treatment. This study compared the effects bevacizumab with those of different control groups (patients treated with cetuximab vs standard of care chemotherapy) than those included in the analyses of Smeets et al. ${ }^{69}$ Nevertheless, findings from all 3 studies indicate a need for additional analyses, using large and diverse patient cohorts to confirm the association between CMS and outcomes of patients treated with bevacizumab.

The side of the colon in which a tumor develops associates with response to therapy. In the FIRE3 trial (NCT00433927) of patients with metastatic colorectal tumors without mutations in RAS, those with left-side colon tumors had a significantly better outcomes after first-line therapy with FOLFIRI and cetuximab (an antibody against EGFR) than with FOLFIRI and bevacizumab (OS time, 38.3 months vs 28 months $)^{168}$. In contrast, in patients with right-side colon tumors, there was no significant difference in survival between patients given either combination (OS 18.3 months vs 23.0 months respectively). Yoshimo et al showed that addition of ramucirumab to FOLFIRI (in the RAISE trial, NCT01183780) as a second-line therapy increased survival times of patients with metastatic colon cancer, regardless of tumor side (or mutational status) ${ }^{169}$. These findings indicate that the side of the colon on which the tumor develops affects to some treatment regimens, but not all.

\section{Future Directions}

Colorectal tumors develop via many different pathways that result in many different TMEs. Mutations in DNA repair genes, the DNA polymerase E gene, and BRAF, as well as the CpG island methylator phenotype, result in high mutation burden and tumor infiltration by lymphocytes. Conversely, APC mutations are associated with lack of lymphocyte infiltration, 
due to activation of beta-catenin. Tumors with mutations in RAS (and probably BRAF) are resistant to anti-EGFR therapies whereas MSI colorectal tumors often respond to immune checkpoint inhibitors.

Different colorectal tumors subtypes therefore respond differently to therapies that target the TME. Integration of data on TMEs with genome and transcriptome profiles might identify the best therapeutic combinations for each patient's tumor type, comprising chemotherapies, immunotherapies, anti-angiogenic therapies, and anti-stromal agents. Immunogenic chemo- and radiotherapies, and oncolytic virus-based therapies, are in development. Cell-based therapies such as autologous tumor-infiltrating lymphocytes or $\mathrm{T}$ cells with chimeric antigen receptors are also being developed and might be effective against tumors that do not induce and immune response. These types of therapies will be selected based on specific features of each patient's tumor and TME. 
Table 1. Cells the Tumor Microenvironment and Functions

\begin{tabular}{|c|c|c|}
\hline \multirow{2}{*}{\multicolumn{3}{|c|}{$\begin{array}{l}\text { Cell Type } \\
\text { Lymphocytes }\end{array}$}} \\
\hline & & \\
\hline NK cells & $\begin{array}{l}\text { MHC class I-negative cells } \\
\text { IgG bound to target cells }\end{array}$ & $\begin{array}{l}\text { killing MHC class I-negative cells } \\
\text { antibody-dependent cellular cytotoxicity of a }\end{array}$ \\
\hline B cells & $\begin{array}{l}\text { native soluble or membrane } \\
\text { antigens }\end{array}$ & $\begin{array}{l}\text { antibody production } \\
\text { antigenic peptide presentation via MHC class }\end{array}$ \\
\hline $\begin{array}{l}\text { CD8+ T CELLS } \\
\text { CD4+ T CELLS }\end{array}$ & $\begin{array}{l}\text { peptides presented by MHC class } \\
\text { I }\end{array}$ & $\begin{array}{l}\text { killing MHC class I-positive cells } \\
\text { regulate responses of T and B cells } \\
\text { produce IFNG }\end{array}$ \\
\hline Th2 cells & $\begin{array}{l}\text { peptides presented by MHC class } \\
\text { II }\end{array}$ & $\begin{array}{l}\text { produce IFNG IL2 } \\
\text { activate CD8+ T cells to become cytotoxic }\end{array}$ \\
\hline T-follicular helper cells & & $\begin{array}{l}\text { produce IL4, IL13 } \\
\text { activate B cells to become antibody-producin }\end{array}$ \\
\hline Th17 cells & & $\begin{array}{l}\text { produce CXCL13 } \\
\text { recruit and activate B cells in TLS }\end{array}$ \\
\hline T-regulatory cells & & $\begin{array}{l}\text { produce IL17 } \\
\text { activate macrophages to produce IL6 and IL8 }\end{array}$ \\
\hline & & $\begin{array}{l}\text { produce IL10, TGFB } \\
\text { suppress responses of T and B cells }\end{array}$ \\
\hline NK T Cells & & killing target cells in an MHC-unrestricted $\mathrm{m}$ \\
\hline Myeloid Cells & & \\
\hline Dendritic cells & danger signals (DAMP, PAMP & $\begin{array}{l}\text { produce IL12, IL18 } \\
\text { present antigen to T cells via MHC I and II }\end{array}$ \\
\hline $\begin{array}{l}\text { Macrophages } \\
\text { M1 }\end{array}$ & $\begin{array}{l}\text { danger signals (DAMP, PAMP) } \\
\text { IgG-coated target cells }\end{array}$ & $\begin{array}{l}\text { produce IL1, IL6 } \\
\text { phagocytosis of target cells } \\
\text { antibody-dependent cytotoxicity of antibody- }\end{array}$ \\
\hline M2 & & $\begin{array}{l}\text { produce VEGF, IL10, TGFB, and compleme } \\
\text { promote angiogenesis, fibroblast activation in }\end{array}$ \\
\hline Mast cells & & produce inflammatory mediators (serotonin, 1 \\
\hline $\begin{array}{l}\text { Polymorphonuclear } \\
\text { cells }\end{array}$ & & phagocytosis of target cells or inflammatory \\
\hline MDSC & danger signals (DAMP, PAMP) & $\begin{array}{l}\text { immature cells of heterogeneous population } \mathrm{f} \\
\text { suppress immune responses }\end{array}$ \\
\hline Stromal cells & & \\
\hline $\begin{array}{l}\text { Follicular dendritic } \\
\text { cells }\end{array}$ & & present antigen to B cells via immune comple \\
\hline CAF & & $\begin{array}{l}\text { produce angiogenic factors (VEGF, CXCL12 } \\
\text { produce immunosuppressive TGFB and M2 } \\
\text { CXCL18 }\end{array}$ \\
\hline
\end{tabular}


originate from tumor cells through the EMT transdifferentiate from endothelial cells, peric form a mechanical barrier preventing entry of produce VEGFA-E, CXCL12, FGF2, and co1 Pericytes support tumor growth through nutrients and $\mathrm{O}$ produce PDGF-BB and regulate vascular func 
Table 2. Clinical Trials of Agents Designed to Target Tumor Stroma

\begin{tabular}{l|ll}
\hline $\begin{array}{l}\text { Trial } \\
\text { anti-angiogenics } \\
\text { bevacizumab }\end{array}$ & Drug combination & Patient population \\
$\begin{array}{l}\text { (avastin) } \\
\text { solstice }\end{array}$ & $\begin{array}{l}\text { 1st line tas } 102+\text { bevacizumab vs } \\
\text { capcitabine + bevacizumab }\end{array}$ & $\begin{array}{l}\text { 854 untreated patients with } \\
\text { MCRC who were not candidates } \\
\text { for irinotecan or oxaliplatin } \\
\text { therapy }\end{array}$ \\
\hline
\end{tabular}

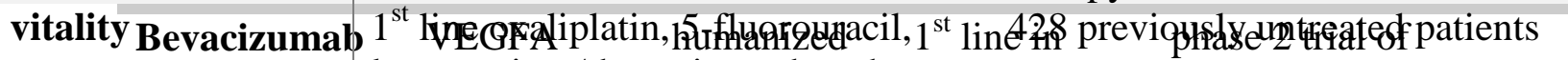
(Avastin)

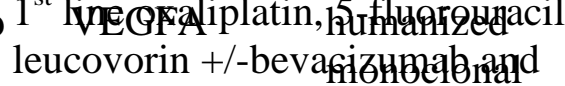
vitamin $C$ vs line oxpltiplatin, 5fluorouracil, leucovgrimst ${ }^{-}$ patients with pembrolizumab, tumors with capecitabine, and Status bevacizumab VEGFA mutations in bevacizumab in bevacizumab + binimetinib (MEK RAS, given patients with

recruiting. due for completion September 2022

bevacizumab (avastin) inhibitor) + prembrolizumab 40 patients with MCRC without a response to prior therapy

recruiting, due for completion December 2020 , CMS2 and CMS4 tumors (Smeets et

bevacizumab (avastin)

$2^{\text {nd }}$ line bevacizumab +5 -

fluorouracil, leucovorin + irinotecan + onvansertib (an inhibitor of pololike kinase 1)

aflibercept + prembrolizumab

aflibercept
(zaltrap)

ramucinumbercept (cyramzzaltrap) ramtas

tas 102G VEGFB, receptor placental growth factor

donafenib (multi
tyrosine kinase
inhibitor)

regorafenib (stivarga) salvage regorafenib + irinotecan vs regorafenib only

$2^{\text {nd }}$ line donafenib vs best supported care

44 patientsunitbremetastatifot be colorectal temgred with sufgetation

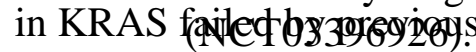
treatment, or patients who are intolerant to, oxaliplatin 78 patients with advanced solid tumors

$2^{\text {nd }}$ linetith patientshuseth advanced

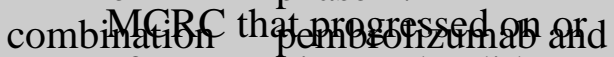
with after, or patientplibere ejpe inot FOLFqR prate, fluerepyorimaideness with oxaliplatinadxintetegasolpd antiors angiogeniqtherapi288959) 510, patients with MCRC that progressed during or within 3 months of final dose of therapy

78 previously treated patients with MCRC that progressed

next-regigimucirumab VEGFR2 (Cyramza) remety $2^{\text {nd }}$ line tas $102+$ regorafenib Fully human 2nd Lhlering or RikhimBAmonths of last

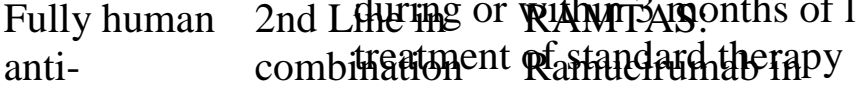
line tas $102+$ regorafenib

folfirinox-r

regorafenib + 5-fluorouracil, leucovorin + irinotecan + oxaliplatin

87 patientcorith(pétastaso946). colorectal tumors with mutant

Regorafenib
regorafenib
(stivarga)

(folfipingxRB. Multi regorafenib + pembrolizumab

\section{SalvageAS phase 1b.}

75 patients with MCRC failed by, or patients who are intolerant to, oxaliplatin, irinotecan, or fluorouracil

\begin{tabular}{l|l} 
checkpoint & BRAF, \\
& BRAF $_{\mathrm{v} 600 \mathrm{E},}$ \\
& FGFR1, \\
& RET
\end{tabular}

full-length RAS ${ }^{\mathrm{b}}$
Recruiting, due

for completion

August 2019 recruiting. due for completion May 2021 chromosome instabilitv $^{\mathrm{b}}$ recruiting. due for completion December 2021 Recruiting, due for completion June2021

CMS4 tumors, based on bevacizumab active not recruiting, due for completion April 2020 recruiting, due for completion June 2023 predicted to have efficacv against Recruiting, due for completion October 2019 recruiting. due for completion March 2022 not yet recruiting, due for completion in July 2022 in PFS and CMS2 and CMS4 in $\mathrm{OS}^{\mathrm{c}, \mathrm{d}}$ 


\begin{tabular}{|c|c|c|c|}
\hline inhibitors & & & \\
\hline $\begin{array}{l}\text { atezolizumab } \\
\text { (Tecentriq) }\end{array}$ & $\begin{array}{l}1^{\text {st }} \text { line folfox } 6+\text { bevacizumab }+ \\
\text { atezolizumab or atezolizumab alone } \\
\text { or FOLFOX6 and bevacizumab }\end{array}$ & 347 patients with MSI tumors & $\begin{array}{l}\text { active, currently } \\
\text { recruiting, due } \\
\text { for completion } \\
\text { April } 2022\end{array}$ \\
\hline $\begin{array}{l}\text { pembrolizumab } \\
\text { (Keytruda) } \\
\text { keynote-177 }\end{array}$ & $\begin{array}{l}1^{\text {st }} \text { line folfox } 6 \text { or folfiri }+ \\
\text { bevacizumab or cetuximab }+/- \\
\text { pembrolizumab }\end{array}$ & $\begin{array}{l}308 \text { patients with MSI tumors or } \\
\text { DNA mismatch repair-deficient } \\
\text { tumors }\end{array}$ & $\begin{array}{l}\text { active, not } \\
\text { recruiting, } \\
\text { due for } \\
\text { completion } \\
\text { February } 2021\end{array}$ \\
\hline $\begin{array}{l}\text { pembrolizumab } \\
\text { (Keytruda) }\end{array}$ & $\begin{array}{l}\text { amg820 (anti csf1r monoclonal } \\
\text { antibody) + pembrolizumab }\end{array}$ & $\begin{array}{l}116 \text { patients with advanced solid } \\
\text { tumors }\end{array}$ & $\begin{array}{l}\text { active, currently } \\
\text { recruiting, due } \\
\text { for completion } \\
\text { May } 2020\end{array}$ \\
\hline $\begin{array}{l}\text { pembrolizumab } \\
\text { (Keytruda) }\end{array}$ & $\begin{array}{l}\text { pembroluzimab + entinostat (a } \\
\text { histone deacetylase inhibitor) }\end{array}$ & $\begin{array}{l}50 \text { patients with DNA mismatch } \\
\text { repair-proficient colorectal } \\
\text { tumors who have not been treated } \\
\text { with anti-PD1 or anti-PDL1 }\end{array}$ & $\begin{array}{l}\text { active, not } \\
\text { recruiting, } \\
\text { due for } \\
\text { completion } \\
\text { August } 2019\end{array}$ \\
\hline $\begin{array}{l}\text { nivolumab } \\
\text { (Opdivo) } \\
\text { checkmate 9x8 }\end{array}$ & $\begin{array}{l}\text { first-line FOLFOX + bevacizumab } \\
+/ \text { nivolumab }\end{array}$ & $\begin{array}{l}180 \text { patients with MMS tumors } \\
\text { or DNA mistach repair proficient } \\
\text { tumors that cannot be treated by } \\
\text { curative resection }\end{array}$ & $\begin{array}{l}\text { active and } \\
\text { recruiting, due } \\
\text { for completion } \\
\text { August } 2022\end{array}$ \\
\hline $\begin{array}{l}\text { nivolumab } \\
\text { (Opdivo) } \\
\text { echo204 }\end{array}$ & $\begin{array}{l}\text { epacadostat (indoleamine } 2,3 \text { - } \\
\text { dioxygenase } 1 \text { inhibitor) }+ \\
\text { nivolumab }+/ \text { - standard of care }\end{array}$ & $\begin{array}{l}307 \text { patients with advanced solid } \\
\text { tumors including colorectal } \\
\text { tumors }\end{array}$ & $\begin{array}{l}\text { active not } \\
\text { recruiting. } \\
\text { due for } \\
\text { completion in } \\
\text { august } 2022\end{array}$ \\
\hline $\begin{array}{l}\text { durvalumab } \\
\text { (imfinzi) } \\
\text { stellar001 }\end{array}$ & $\begin{array}{l}\text { durvalumab+ IPH5401 (human } \\
\text { monoclonal antibody against C5AR) }\end{array}$ & $\begin{array}{l}100 \text { patients with advanced solid } \\
\text { tumors }\end{array}$ & $\begin{array}{l}\text { active and } \\
\text { recruiting, } \\
\text { due for } \\
\text { completion June } \\
2021\end{array}$ \\
\hline $\begin{array}{l}\text { durvalumab } \\
\text { (imfinzi) }\end{array}$ & $\begin{array}{l}\text { durvalumab }+ \text { oncos102 (an } \\
\text { adenovirus that encodes GMCSF) }\end{array}$ & $\begin{array}{l}78 \text { patients with advanced } \\
\text { peritoneal disease failed by } \\
\text { chemotherapy }\end{array}$ & $\begin{array}{l}\text { active not } \\
\text { recruiting, } \\
\text { due for } \\
\text { completion } \\
\text { October } 2022\end{array}$ \\
\hline other & & & \\
\hline $\begin{array}{l}\text { c-kit/mast cell } \\
\text { inhibitor }\end{array}$ & $\begin{array}{l}\text { third- or fourth-line masitinib }+ \\
\text { FOLFIRI vs best supportive care }\end{array}$ & $\begin{array}{l}219 \text { patients with MCRC failed } \\
\text { by second- or third-line therapy }\end{array}$ & $\begin{array}{l}\text { active not } \\
\text { recruiting, } \\
\text { due for } \\
\text { completion } \\
\text { December } 2020\end{array}$ \\
\hline $\begin{array}{l}\text { CCR1 and CCR5 } \\
\text { antagonist }\end{array}$ & $\begin{array}{l}\text { BMS } 813160+/ \text { - folfiri/nab- } \\
\text { paclitaxel/gemcitabine or nivolumab }\end{array}$ & $\begin{array}{l}348 \text { patients with advanced } \\
\text { colorectal or pancreatic tumors }\end{array}$ & $\begin{array}{l}\text { active, not } \\
\text { recruiting } \\
\text { due for } \\
\text { completion } \\
\text { December } 2021\end{array}$ \\
\hline
\end{tabular}


MCRC, metastatic colorectal cancer; MMRP, DNA mismatch repair proficient; PLK1, polo-like kinase1; 
1. Fridman WH, Pagès F, Sautès-Fridman C, et al. The immune contexture in human tumours: impact on clinical outcome. Nat Rev Cancer 2012;12:298-306.

2. Fridman WH, Zitvogel L, Sautès-Fridman C, et al. The immune contexture in cancer prognosis and treatment. Nature Reviews Clinical Oncology 2017;14:717-734.

3. Kobayashi H, Enomoto A, Woods SL, et al. Cancer-associated fibroblasts in gastrointestinal cancer. Nat Rev Gastroenterol Hepatol 2019.

4. Bindea G, Mlecnik B, Tosolini M, et al. Spatiotemporal dynamics of intratumoral immune cells reveal the immune landscape in human cancer. Immunity 2013;39:782-795.

5. Dolcetti R, Viel A, Doglioni C, et al. High prevalence of activated intraepithelial cytotoxic T lymphocytes and increased neoplastic cell apoptosis in colorectal carcinomas with microsatellite instability. Am J Pathol 1999;154:1805-1813.

6. Spranger S, Bao R, Gajewski TF. Melanoma-intrinsic $\beta$-catenin signalling prevents anti-tumour immunity. Nature 2015;523:231-235.

7. Luke JJ, Bao R, Sweis RF, et al. WNT/ $\beta$-catenin pathway activation correlates with immune exclusion across human cancers. Clin Cancer Res 2019.

8. Becht E, Giraldo NA, Germain C, et al. Immune Contexture, Immunoscore, and Malignant Cell Molecular Subgroups for Prognostic and Theranostic Classifications of Cancers. Adv Immunol 2016;130:95-190.

9. Lièvre A, Bachet J-B, Le Corre D, et al. KRAS mutation status is predictive of response to cetuximab therapy in colorectal cancer. Cancer Res 2006;66:3992-3995.

10. Van Emburgh BO, Arena S, Siravegna G, et al. Acquired RAS or EGFR mutations and duration of response to EGFR blockade in colorectal cancer. Nat Commun 2016;7:13665.

11. Zdanov S, Mandapathil M, Abu Eid R, et al. Mutant KRAS Conversion of Conventional T Cells into Regulatory T Cells. Cancer Immunol Res 2016;4:354-365.

12. Bibeau F, Lopez-Crapez E, Di Fiore F, et al. Impact of Fc\{gamma\}RIIa-

Fc $\{$ gamma $\}$ RIIIa polymorphisms and KRAS mutations on the clinical outcome of patients with metastatic colorectal cancer treated with cetuximab plus irinotecan. J Clin Oncol 2009;27:1122-1129.

13. Vogelstein B, Fearon ER, Hamilton SR, et al. Genetic Alterations during ColorectalTumor Development. New England Journal of Medicine 1988;319:525-532.

14. Baker KT, Salk JJ, Brentnall TA, et al. Precancer in ulcerative colitis: the role of the field effect and its clinical implications. Carcinogenesis 2018;39:11-20.

15. Dyson JK, Rutter MD. Colorectal cancer in inflammatory bowel disease: what is the real magnitude of the risk? World J Gastroenterol 2012;18:3839-3848.

16. Hovde $\varnothing$, Kempski-Monstad I, Småstuen MC, et al. Mortality and causes of death in Crohn's disease: results from 20 years of follow-up in the IBSEN study. Gut 2014;63:771775.

17. Parang B, Barrett CW, Williams CS. AOM/DSS Model of Colitis-Associated Cancer. Methods Mol Biol 2016;1422:297-307.

18. Uronis JM, Mühlbauer M, Herfarth HH, et al. Modulation of the intestinal microbiota alters colitis-associated colorectal cancer susceptibility. PLoS ONE 2009;4:e6026.

19. Schwitalla S, Ziegler PK, Horst D, et al. Loss of p53 in Enterocytes Generates an Inflammatory Microenvironment Enabling Invasion and Lymph Node Metastasis of Carcinogen-Induced Colorectal Tumors. Cancer Cell 2013;23:93-106.

20. Grivennikov SI, Wang K, Mucida D, et al. Adenoma-linked barrier defects and microbial products drive IL-23/IL-17-mediated tumour growth. Nature 2012;491:254-258.

21. Tosolini M, Kirilovsky A, Mlecnik B, et al. Clinical impact of different classes of infiltrating T cytotoxic and helper cells (Th1, th2, treg, th17) in patients with colorectal cancer. Cancer Res 2011;71:1263-1271. 
22. Schwabe RF, Jobin C. The microbiome and cancer. Nat Rev Cancer 2013;13:800-

812.

23. Latham A, Srinivasan P, Kemel Y, et al. Microsatellite Instability Is Associated With the Presence of Lynch Syndrome Pan-Cancer. J Clin Oncol 2019;37:286-295.

24. Pagès F, Berger A, Camus M, et al. Effector memory T cells, early metastasis, and survival in colorectal cancer. N Engl J Med 2005;353:2654-2666.

25. Mauffrey P, Tchitchek N, Barroca V, et al. Progenitors from the central nervous system drive neurogenesis in cancer. Nature 2019;569:672.

26. Qi X-W, Xia S-H, Yin Y, et al. Expression features of CXCR5 and its ligand, CXCL13 associated with poor prognosis of advanced colorectal cancer. Eur Rev Med Pharmacol Sci 2014;18:1916-1924.

27. Weiss N, Deboux C, Chaverot N, et al. IL8 and CXCL13 are potent chemokines for the recruitment of human neural precursor cells across brain endothelial cells. Journal of Neuroimmunology 2010;223:131-134.

28. Kizil C, Dudczig S, Kyritsis N, et al. The chemokine receptor cxcr5 regulates the regenerative neurogenesis response in the adult zebrafish brain. Neural Dev 2012;7:27.

29. Meijer J, Zeelenberg IS, Sipos B, et al. The CXCR5 chemokine receptor is expressed by carcinoma cells and promotes growth of colon carcinoma in the liver. Cancer Res 2006;66:9576-9582.

30. Cremonesi E, Governa V, Garzon JFG, et al. Gut microbiota modulate T cell trafficking into human colorectal cancer. Gut 2018;67:1984-1994.

31. Sautès-Fridman C, Petitprez F, Calderaro J, et al. Tertiary lymphoid structures in the era of cancer immunotherapy. Nat Rev Cancer 2019;19:307-325.

32. Kobayashi H, Enomoto A, Woods SL, et al. Cancer-associated fibroblasts in gastrointestinal cancer. Nature Reviews Gastroenterology \& Hepatology 2019:1.

33. Volz NB, Stintzing S, Zhang W, et al. Genes involved in pericyte-driven tumor maturation predict treatment benefit of first-line FOLFIRI plus bevacizumab in patients with metastatic colorectal cancer. Pharmacogenomics J 2015;15:69-76.

34. Eberhard A, Kahlert S, Goede V, et al. Heterogeneity of angiogenesis and blood vessel maturation in human tumors: implications for antiangiogenic tumor therapies. Cancer Res 2000;60:1388-1393.

35. Platonova S, Cherfils-Vicini J, Damotte D, et al. Profound coordinated alterations of intratumoral NK cell phenotype and function in lung carcinoma. Cancer Res 2011;71:54125422.

36. Dieu-Nosjean M-C, Giraldo NA, Kaplon H, et al. Tertiary lymphoid structures, drivers of the anti-tumor responses in human cancers. Immunol Rev 2016;271:260-275.

37. Bindea G, Mlecnik B, Tosolini M, et al. Spatiotemporal dynamics of intratumoral immune cells reveal the immune landscape in human cancer. Immunity 2013;39:782-795.

38. Grasso CS, Giannakis M, Wells DK, et al. Genetic Mechanisms of Immune Evasion in Colorectal Cancer. Cancer Discov 2018;8:730-749.

39. Findeisen P, Kloor M, Merx S, et al. T25 repeat in the 3' untranslated region of the CASP2 gene: a sensitive and specific marker for microsatellite instability in colorectal cancer. Cancer Res 2005;65:8072-8078.

40. Pino MS, Chung DC. The chromosomal instability pathway in colon cancer. Gastroenterology 2010;138:2059-2072.

41. Mlecnik B, Bindea G, Angell HK, et al. Integrative Analyses of Colorectal Cancer Show Immunoscore Is a Stronger Predictor of Patient Survival Than Microsatellite Instability. Immunity 2016;44:698-711.

42. Becht E, Reyniès A de, Giraldo NA, et al. Immune and Stromal Classification of Colorectal Cancer Is Associated with Molecular Subtypes and Relevant for Precision 
Immunotherapy. Clin Cancer Res 2016;22:4057-4066.

43. Palles C, Cazier J-B, Howarth KM, et al. Germline mutations affecting the proofreading domains of POLE and POLD1 predispose to colorectal adenomas and carcinomas. Nat Genet 2013;45:136-144.

44. Domingo E, Freeman-Mills L, Rayner E, et al. Somatic POLE proofreading domain mutation, immune response, and prognosis in colorectal cancer: a retrospective, pooled biomarker study. Lancet Gastroenterol Hepatol 2016;1:207-216.

45. Glaire MA, Brown M, Church DN, et al. Cancer predisposition syndromes: lessons for truly precision medicine. J Pathol 2017;241:226-235.

46. Roock WD, Vriendt VD, Normanno N, et al. KRAS, BRAF, PIK3CA, and PTEN mutations: implications for targeted therapies in metastatic colorectal cancer. The Lancet Oncology 2011;12:594-603.

47. Amado RG, Wolf M, Peeters M, et al. Wild-type KRAS is required for panitumumab efficacy in patients with metastatic colorectal cancer. J Clin Oncol 2008;26:1626-1634.

48. De Roock W, Jonker DJ, Di Nicolantonio F, et al. Association of KRAS p.G13D mutation with outcome in patients with chemotherapy-refractory metastatic colorectal cancer treated with cetuximab. JAMA 2010;304:1812-1820.

49. Allegra CJ, Rumble RB, Hamilton SR, et al. Extended RAS Gene Mutation Testing in Metastatic Colorectal Carcinoma to Predict Response to Anti-Epidermal Growth Factor Receptor Monoclonal Antibody Therapy: American Society of Clinical Oncology Provisional Clinical Opinion Update 2015. J Clin Oncol 2016;34:179-185.

50. Van Cutsem E, Tabernero J, Lakomy R, et al. Addition of aflibercept to fluorouracil, leucovorin, and irinotecan improves survival in a phase III randomized trial in patients with metastatic colorectal cancer previously treated with an oxaliplatin-based regimen. J Clin Oncol 2012;30:3499-3506.

51. Ikenoue T, Hikiba Y, Kanai F, et al. Functional analysis of mutations within the kinase activation segment of B-Raf in human colorectal tumors. Cancer Res 2003;63:81328137.

52. Liao W, Overman MJ, Boutin AT, et al. KRAS-IRF2 Axis Drives Immune Suppression and Immune Therapy Resistance in Colorectal Cancer. Cancer Cell 2019;35:559-572.e7.

53. Nakadate Y, Kodera Y, Kitamura Y, et al. KRAS mutation confers resistance to antibody-dependent cellular cytotoxicity of cetuximab against human colorectal cancer cells. Int J Cancer 2014;134:2146-2155.

54. Zhao B, Wang L, Qiu H, et al. Mechanisms of resistance to anti-EGFR therapy in colorectal cancer. Oncotarget 2017;8:3980-4000.

55. Cancer Genome Atlas Network. Comprehensive molecular characterization of human colon and rectal cancer. Nature 2012;487:330-337.

56. Roepman P, Schlicker A, Tabernero J, et al. Colorectal cancer intrinsic subtypes predict chemotherapy benefit, deficient mismatch repair and epithelial-to-mesenchymal transition. Int J Cancer 2014;134:552-562.

57. Budinska E, Popovici V, Tejpar S, et al. Gene expression patterns unveil a new level of molecular heterogeneity in colorectal cancer. J Pathol 2013;231:63-76.

58. Schlicker A, Beran G, Chresta CM, et al. Subtypes of primary colorectal tumors correlate with response to targeted treatment in colorectal cell lines. BMC Med Genomics 2012;5:66.

59. Sadanandam A, Lyssiotis CA, Homicsko K, et al. A colorectal cancer classification system that associates cellular phenotype and responses to therapy. Nat Med 2013;19:619625 .

60. Marisa L, Reyniès A de, Duval A, et al. Gene expression classification of colon 
cancer into molecular subtypes: characterization, validation, and prognostic value. PLoS Med 2013;10:e1001453.

61. De Sousa E Melo F, Wang X, Jansen M, et al. Poor-prognosis colon cancer is defined by a molecularly distinct subtype and develops from serrated precursor lesions. Nat Med 2013;19:614-618.

62. Perez-Villamil B, Romera-Lopez A, Hernandez-Prieto S, et al. Colon cancer molecular subtypes identified by expression profiling and associated to stroma, mucinous type and different clinical behavior. BMC Cancer 2012;12:260.

63. Guinney J, Dienstmann R, Wang X, et al. The consensus molecular subtypes of colorectal cancer. Nat Med 2015;21:1350-1356.

64. Herman JG, Umar A, Polyak K, et al. Incidence and functional consequences of hMLH1 promoter hypermethylation in colorectal carcinoma. Proc Natl Acad Sci USA 1998;95:6870-6875.

65. Dienstmann R, Vermeulen L, Guinney J, et al. Consensus molecular subtypes and the evolution of precision medicine in colorectal cancer. Nat Rev Cancer 2017;17:79-92.

66. Alderdice M, Richman SD, Gollins S, et al. Prospective patient stratification into robust cancer-cell intrinsic subtypes from colorectal cancer biopsies. J Pathol 2018;245:1928.

67. Lal N, Beggs AD, Willcox BE, et al. An immunogenomic stratification of colorectal cancer: Implications for development of targeted immunotherapy. Oncoimmunology 2015;4:e976052.

68. Dijk E van, Biesma HD, Cordes M, et al. Loss of Chromosome 18q11.2-q12.1 Is Predictive for Survival in Patients With Metastatic Colorectal Cancer Treated With Bevacizumab. J Clin Oncol 2018;36:2052-2060.

69. Smeets D, Miller IS, O'Connor DP, et al. Copy number load predicts outcome of metastatic colorectal cancer patients receiving bevacizumab combination therapy. Nat Commun 2018;9:4112.

70. Lee GH, Malietzis G, Askari A, et al. Is right-sided colon cancer different to left-sided colorectal cancer? - a systematic review. Eur J Surg Oncol 2015;41:300-308.

71. Kim K, Castro EJT, Shim H, et al. Differences Regarding the Molecular Features and Gut Microbiota Between Right and Left Colon Cancer. Ann Coloproctol 2018;34:280-285.

72. Berntsson J, Eberhard J, Nodin B, et al. Expression of programmed cell death protein 1 (PD-1) and its ligand PD-L1 in colorectal cancer: Relationship with sidedness and prognosis. Oncoimmunology 2018;7:e1465165.

73. Baran B, Mert Ozupek N, Yerli Tetik N, et al. Difference Between Left-Sided and Right-Sided Colorectal Cancer: A Focused Review of Literature. Gastroenterology Res 2018;11:264-273.

74. Pagès F, Berger A, Camus M, et al. Effector memory T cells, early metastasis, and survival in colorectal cancer. N Engl J Med 2005;353:2654-2666.

75. Galon J, Costes A, Sanchez-Cabo F, et al. Type, density, and location of immune cells within human colorectal tumors predict clinical outcome. Science 2006;313:1960-1964.

76. Halama N, Michel S, Kloor M, et al. Localization and density of immune cells in the invasive margin of human colorectal cancer liver metastases are prognostic for response to chemotherapy. Cancer Res 2011;71:5670-5677.

77. Remark R, Alifano M, Cremer I, et al. Characteristics and clinical impacts of the immune environments in colorectal and renal cell carcinoma lung metastases: influence of tumor origin. Clin Cancer Res 2013;19:4079-4091.

78. Mlecnik B, Tosolini M, Kirilovsky A, et al. Histopathologic-based prognostic factors of colorectal cancers are associated with the state of the local immune reaction. J Clin Oncol 2011;29:610-618. 
79. Galon J, Fridman W-H, Pagès F. The adaptive immunologic microenvironment in colorectal cancer: a novel perspective. Cancer Res 2007;67:1883-1886.

80. Angelova M, Mlecnik B, Vasaturo A, et al. Evolution of Metastases in Space and Time under Immune Selection. Cell 2018;175:751-765.e16.

81. Ijsselsteijn ME, Petitprez F, Lacroix L, et al. Revisiting immune escape in colorectal cancer in the era of immunotherapy. Br J Cancer 2019.

82. Middha S, Yaeger R, Shia J, et al. Majority of B2M-Mutant and -Deficient Colorectal Carcinomas Achieve Clinical Benefit From Immune Checkpoint Inhibitor Therapy and Are Microsatellite Instability-High. JCO Precision Oncology 2019:1-14.

83. Ozcan M, Janikovits J, Knebel Doeberitz M von, et al. Complex pattern of immune evasion in MSI colorectal cancer. Oncoimmunology 2018;7:e1445453.

84. Mlecnik B, Tosolini M, Charoentong P, et al. Biomolecular network reconstruction identifies T-cell homing factors associated with survival in colorectal cancer.

Gastroenterology 2010;138:1429-1440.

85. Mlecnik B, Bindea G, Kirilovsky A, et al. The tumor microenvironment and Immunoscore are critical determinants of dissemination to distant metastasis. Sci Transl Med 2016;8:327ra26.

86. Becht E, Giraldo NA, Lacroix L, et al. Estimating the population abundance of tissueinfiltrating immune and stromal cell populations using gene expression. Genome Biol 2016;17:218.

87. Di Caro G, Bergomas F, Grizzi F, et al. Occurrence of tertiary lymphoid tissue is associated with $\mathrm{T}$-cell infiltration and predicts better prognosis in early-stage colorectal cancers. Clin Cancer Res 2014;20:2147-2158.

88. Pagès $\mathrm{F}$, Mlecnik $\mathrm{B}$, Marliot $\mathrm{F}$, et al. International validation of the consensus Immunoscore for the classification of colon cancer: a prognostic and accuracy study. Lancet 2018;391:2128-2139.

89. Castellarin M, Warren RL, Freeman JD, et al. Fusobacterium nucleatum infection is prevalent in human colorectal carcinoma. Genome Res 2012;22:299-306.

90. Mima K, Sukawa Y, Nishihara R, et al. Fusobacterium nucleatum and T Cells in Colorectal Carcinoma. JAMA Oncol 2015;1:653-661.

91. Mima K, Nishihara R, Qian ZR, et al. Fusobacterium nucleatum in colorectal carcinoma tissue and patient prognosis. Gut 2016;65:1973-1980.

92. Zhou Z, Chen J, Yao H, et al. Fusobacterium and Colorectal Cancer. Front Oncol 2018;8. Available at: https://www.frontiersin.org/articles/10.3389/fonc.2018.00371/full\#B73 [Accessed June 9, 2019].

93. Herrera M, Herrera A, Domínguez G, et al. Cancer-associated fibroblast and M2 macrophage markers together predict outcome in colorectal cancer patients. Cancer Sci 2013;104:437-444.

94. Llosa NJ, Cruise M, Tam A, et al. The vigorous immune microenvironment of microsatellite instable colon cancer is balanced by multiple counter-inhibitory checkpoints. Cancer Discov 2015;5:43-51.

95. Galdiero MR, Bianchi P, Grizzi F, et al. Occurrence and significance of tumorassociated neutrophils in patients with colorectal cancer. Int J Cancer 2016;139:446-456.

96. Saadalla AM, Osman A, Gurish MF, et al. Mast cells promote small bowel cancer in a tumor stage-specific and cytokine-dependent manner. Proc Natl Acad Sci USA 2018;115:1588-1592.

97. Tauriello DVF, Palomo-Ponce S, Stork D, et al. TGF $\beta$ drives immune evasion in genetically reconstituted colon cancer metastasis. Nature 2018;554:538-543.

98. Turley SJ, Cremasco V, Astarita JL. Immunological hallmarks of stromal cells in the tumour microenvironment. Nat Rev Immunol 2015;15:669-682. 
99. De Palma M, Biziato D, Petrova TV. Microenvironmental regulation of tumour angiogenesis. Nat Rev Cancer 2017;17:457-474.

100. Le DT, Uram JN, Wang H, et al. PD-1 Blockade in Tumors with Mismatch-Repair Deficiency. N Engl J Med 2015;372:2509-2520.

101. Le DT, Durham JN, Smith KN, et al. Mismatch repair deficiency predicts response of solid tumors to PD-1 blockade. Science 2017;357:409-413.

102. Overman MJ, McDermott R, Leach JL, et al. Nivolumab in patients with metastatic DNA mismatch repair-deficient or microsatellite instability-high colorectal cancer (CheckMate 142): an open-label, multicentre, phase 2 study. Lancet Oncol 2017;18:11821191.

103. Ganesh K, Stadler ZK, Cercek A, et al. Immunotherapy in colorectal cancer: rationale, challenges and potential. Nat Rev Gastroenterol Hepatol 2019.

104. Samstein RM, Lee C-H, Shoushtari AN, et al. Tumor mutational load predicts survival after immunotherapy across multiple cancer types. Nat Genet 2019;51:202-206.

105. Kather JN, Pearson AT, Halama N, et al. Deep learning can predict microsatellite instability directly from histology in gastrointestinal cancer. Nature Medicine 2019:1.

106. Ansell SM, Lesokhin AM, Borrello I, et al. PD-1 blockade with nivolumab in relapsed or refractory Hodgkin's lymphoma. N Engl J Med 2015;372:311-319.

107. Mlecnik B, Bindea G, Angell HK, et al. Integrative Analyses of Colorectal Cancer Show Immunoscore Is a Stronger Predictor of Patient Survival Than Microsatellite Instability. Immunity 2016;44:698-711.

108. Reis ES, Mastellos DC, Ricklin D, et al. Complement in cancer: untangling an intricate relationship. Nat Rev Immunol 2018;18:5-18.

109. Conway EM, Pikor LA, Kung SHY, et al. Macrophages, Inflammation, and Lung Cancer. Am J Respir Crit Care Med 2016;193:116-130.

110. Arango Duque G, Descoteaux A. Macrophage cytokines: involvement in immunity and infectious diseases. Front Immunol 2014;5:491.

111. Roumenina LT, Daugan MV, Noe R, et al. Tumor cells hijack macrophage-produced complement C1q to promote tumor growth. Cancer Immunol Res 2019.

112. Fukumura D, Kloepper J, Amoozgar Z, et al. Enhancing cancer immunotherapy using antiangiogenics: opportunities and challenges. Nat Rev Clin Oncol 2018;15:325-340.

113. Halama N, Zoernig I, Berthel A, et al. Tumoral Immune Cell Exploitation in Colorectal Cancer Metastases Can Be Targeted Effectively by Anti-CCR5 Therapy in Cancer Patients. Cancer Cell 2016;29:587-601.

114. Katz LH, Li Y, Chen J-S, et al. Targeting TGF- $\beta$ signaling in cancer. Expert Opin Ther Targets 2013;17:743-760.

115. Mannino MH, Zhu Z, Xiao H, et al. The paradoxical role of IL-10 in immunity and cancer. Cancer Letters 2015;367:103-107.

116. Huang T, Lin C, Zhong LLD, et al. Targeting histone methylation for colorectal cancer. Therap Adv Gastroenterol 2017;10:114-131.

117. Bloy N, Garcia P, Laumont CM, et al. Immunogenic stress and death of cancer cells: Contribution of antigenicity vs adjuvanticity to immunosurveillance. Immunol Rev 2017;280:165-174.

118. Twumasi-Boateng K, Pettigrew JL, Kwok YYE, et al. Oncolytic viruses as engineering platforms for combination immunotherapy. Nat Rev Cancer 2018;18:419-432.

119. Miranda A, Hamilton PT, Zhang AW, et al. Cancer stemness, intratumoral heterogeneity, and immune response across cancers. PNAS 2019;116:9020-9029.

120. Nagy JA, Chang S-H, Shih S-C, et al. Heterogeneity of the tumor vasculature. Semin Thromb Hemost 2010;36:321-331.

121. Bergers G, Benjamin LE. Tumorigenesis and the angiogenic switch. Nat Rev Cancer 
2003;3:401-410.

122. Eichmann A, Simons M. VEGF signaling inside vascular endothelial cells and beyond. Curr Opin Cell Biol 2012;24:188-193.

123. Ding C, Li L, Yang T, et al. Combined application of anti-VEGF and anti-EGFR attenuates the growth and angiogenesis of colorectal cancer mainly through suppressing AKT and ERK signaling in mice model. BMC Cancer 2016;16:791.

124. Álvarez-Aznar A, Muhl L, Gaengel K. VEGF Receptor Tyrosine Kinases: Key Regulators of Vascular Function. Curr Top Dev Biol 2017;123:433-482.

125. Dineen SP, Lynn KD, Holloway SE, et al. Vascular endothelial growth factor receptor 2 mediates macrophage infiltration into orthotopic pancreatic tumors in mice. Cancer Res 2008;68:4340-4346.

126. Brahimi-Horn MC, Bellot G, Pouysségur J. Hypoxia and energetic tumour metabolism. Curr Opin Genet Dev 2011;21:67-72.

127. Wang Y, Yao X, Ge J, et al. Can vascular endothelial growth factor and microvessel density be used as prognostic biomarkers for colorectal cancer? A systematic review and meta-analysis. ScientificWorldJournal 2014;2014:102736.

128. Mohamed SY, Mohammed HL, Ibrahim HM, et al. Role of VEGF, CD105, and CD31 in the Prognosis of Colorectal Cancer Cases. J Gastrointest Cancer 2019;50:23-34.

129. Zhu B, Zhou L, Yu L, et al. Evaluation of the correlation of vasculogenic mimicry, ALDH1, KAI1 and microvessel density in the prediction of metastasis and prognosis in colorectal carcinoma. BMC Surg 2017;17:47.

130. Mitselou A, Galani V, Skoufi U, et al. Syndecan-1, Epithelial-Mesenchymal Transition Markers (E-cadherin/ $\beta$-catenin) and Neoangiogenesis-related Proteins (PCAM-1 and Endoglin) in Colorectal Cancer. Anticancer Res 2016;36:2271-2280.

131. Väyrynen SA, Väyrynen JP, Klintrup K, et al. Clinical impact and network of determinants of tumour necrosis in colorectal cancer. Br J Cancer 2016;114:1334-1342. 132. Nanni O, Volpi A, Frassineti GL, et al. Role of biological markers in the clinical outcome of colon cancer. Br J Cancer 2002;87:868-875.

133. Shan Y-S, Lee J-C, Chow N-H, et al. Immunohistochemical microvessel count is not a reliable prognostic predictor in colorectal carcinoma. Hepatogastroenterology 2003;50:1316-1320.

134. Prall F, Gringmuth U, Nizze H, et al. Microvessel densities and microvascular architecture in colorectal carcinomas and their liver metastases: significant correlation of high microvessel densities with better survival. Histopathology 2003;42:482-491.

135. Cianchi F, Palomba A, Messerini L, et al. Tumor angiogenesis in lymph nodenegative rectal cancer: correlation with clinicopathological parameters and prognosis. Ann Surg Oncol 2002;9:20-26.

136. Des Guetz G, Uzzan B, Nicolas P, et al. Microvessel density and VEGF expression are prognostic factors in colorectal cancer. Meta-analysis of the literature. Br J Cancer 2006;94:1823-1832.

137. Jubb AM, Hurwitz HI, Bai W, et al. Impact of vascular endothelial growth factor-A expression, thrombospondin-2 expression, and microvessel density on the treatment effect of bevacizumab in metastatic colorectal cancer. J Clin Oncol 2006;24:217-227.

138. Hurwitz H, Fehrenbacher L, Novotny W, et al. Bevacizumab plus irinotecan, fluorouracil, and leucovorin for metastatic colorectal cancer. N Engl J Med 2004;350:23352342.

139. Tampellini M, Sonetto C, Scagliotti GV. Novel anti-angiogenic therapeutic strategies in colorectal cancer. Expert Opin Investig Drugs 2016;25:507-520.

140. Yang JC, Haworth L, Sherry RM, et al. A randomized trial of bevacizumab, an antivascular endothelial growth factor antibody, for metastatic renal cancer. N Engl J Med 
2003;349:427-434.

141. Ince WL, Jubb AM, Holden SN, et al. Association of k-ras, b-raf, and p53 status with the treatment effect of bevacizumab. J Natl Cancer Inst 2005;97:981-989.

142. Bennouna J, Sastre J, Arnold D, et al. Continuation of bevacizumab after first progression in metastatic colorectal cancer (ML18147): a randomised phase 3 trial. Lancet Oncol 2013;14:29-37.

143. Ciombor KK, Berlin J. Aflibercept--a decoy VEGF receptor. Curr Oncol Rep 2014; $16: 368$.

144. Tabernero J, Hozak RR, Yoshino T, et al. Analysis of angiogenesis biomarkers for ramucirumab efficacy in patients with metastatic colorectal cancer from RAISE, a global, randomized, double-blind, phase III study. Ann Oncol 2018;29:602-609.

145. Pepper MS. Lymphangiogenesis and tumor metastasis: myth or reality? Clin Cancer Res 2001;7:462-468.

146. Huang C, Chen Y. Lymphangiogenesis and colorectal cancer. Saudi Med J 2017;38:237-244.

147. Du B, Yang Z-Y, Zhong X-Y, et al. Metastasis-associated protein 1 induces VEGF-C and facilitates lymphangiogenesis in colorectal cancer. World J Gastroenterol 2011;17:12191226.

148. Sundlisaeter E, Dicko A, Sakariassen PØ, et al. Lymphangiogenesis in colorectal cancer--prognostic and therapeutic aspects. Int J Cancer 2007;121:1401-1409.

149. Joukov V, Pajusola K, Kaipainen A, et al. A novel vascular endothelial growth factor, VEGF-C, is a ligand for the Flt4 (VEGFR-3) and KDR (VEGFR-2) receptor tyrosine kinases. EMBO J 1996;15:290-298.

150. Achen MG, Jeltsch M, Kukk E, et al. Vascular endothelial growth factor D (VEGF-D) is a ligand for the tyrosine kinases VEGF receptor 2 (Flk1) and VEGF receptor 3 (Flt4). Proc Natl Acad Sci USA 1998;95:548-553.

151. Clavin NW, Avraham T, Fernandez J, et al. TGF-beta1 is a negative regulator of lymphatic regeneration during wound repair. Am J Physiol Heart Circ Physiol 2008;295:H2113-2127.

152. Li H, Courtois ET, Sengupta D, et al. Reference component analysis of single-cell transcriptomes elucidates cellular heterogeneity in human colorectal tumors. Nat Genet 2017;49:708-718.

153. Villalba M, Evans SR, Vidal-Vanaclocha F, et al. Role of TGF- $\beta$ in metastatic colon cancer: it is finally time for targeted therapy. Cell Tissue Res 2017;370:29-39.

154. Adnane L, Trail PA, Taylor I, et al. Sorafenib (BAY 43-9006, Nexavar), a dual-action inhibitor that targets RAF/MEK/ERK pathway in tumor cells and tyrosine kinases VEGFR/PDGFR in tumor vasculature. Meth Enzymol 2006;407:597-612.

155. Tabernero J, Garcia-Carbonero R, Cassidy J, et al. Sorafenib in combination with oxaliplatin, leucovorin, and fluorouracil (modified FOLFOX6) as first-line treatment of metastatic colorectal cancer: the RESPECT trial. Clin Cancer Res 2013;19:2541-2550.

156. Scartozzi M, Vincent L, Chiron M, et al. Aflibercept, a New Way to Target Angiogenesis in the Second Line Treatment of Metastatic Colorectal Cancer (mCRC). Target Oncol 2016;11:489-500.

157. Lambrechts D, Claes B, Delmar P, et al. VEGF pathway genetic variants as biomarkers of treatment outcome with bevacizumab: an analysis of data from the AViTA and AVOREN randomised trials. Lancet Oncol 2012;13:724-733.

158. Haas S de, Delmar P, Bansal AT, et al. Genetic variability of VEGF pathway genes in six randomized phase III trials assessing the addition of bevacizumab to standard therapy.

Angiogenesis 2014;17:909-920.

159. Kopetz S, Hoff PM, Morris JS, et al. Phase II trial of infusional fluorouracil, 
irinotecan, and bevacizumab for metastatic colorectal cancer: efficacy and circulating angiogenic biomarkers associated with therapeutic resistance. J Clin Oncol 2010;28:453-459. 160. Loupakis F, Cremolini C, Fioravanti A, et al. Pharmacodynamic and pharmacogenetic angiogenesis-related markers of first-line FOLFOXIRI plus bevacizumab schedule in metastatic colorectal cancer. Br J Cancer 2011;104:1262-1269.

161. Weickhardt AJ, Williams DS, Lee CK, et al. Vascular endothelial growth factor D expression is a potential biomarker of bevacizumab benefit in colorectal cancer. Br J Cancer 2015;113:37-45.

162. Schneider BP, Wang M, Radovich M, et al. Association of vascular endothelial growth factor and vascular endothelial growth factor receptor-2 genetic polymorphisms with outcome in a trial of paclitaxel compared with paclitaxel plus bevacizumab in advanced breast cancer: ECOG 2100. J Clin Oncol 2008;26:4672-4678.

163. Haan JC, Labots M, Rausch C, et al. Genomic landscape of metastatic colorectal cancer. Nat Commun 2014;5:5457.

164. Lambrechts D, Lenz H-J, Haas S de, et al. Markers of response for the antiangiogenic agent bevacizumab. J Clin Oncol 2013;31:1219-1230.

165. Tebbutt NC, Wilson K, Gebski VJ, et al. Capecitabine, bevacizumab, and mitomycin in first-line treatment of metastatic colorectal cancer: results of the Australasian

Gastrointestinal Trials Group Randomized Phase III MAX Study. J Clin Oncol 2010;28:3191-3198.

166. Mooi JK, Wirapati P, Asher R, et al. The prognostic impact of consensus molecular subtypes (CMS) and its predictive effects for bevacizumab benefit in metastatic colorectal cancer: molecular analysis of the AGITG MAX clinical trial. Ann Oncol 2018;29:22402246.

167. Venook AP, Niedzwiecki D, Lenz H-J, et al. Effect of First-Line Chemotherapy Combined With Cetuximab or Bevacizumab on Overall Survival in Patients With KRAS Wild-Type Advanced or Metastatic Colorectal Cancer: A Randomized Clinical Trial. JAMA 2017;317:2392-2401.

168. Heinemann V, Weikersthal LF von, Decker T, et al. FOLFIRI plus cetuximab versus FOLFIRI plus bevacizumab as first-line treatment for patients with metastatic colorectal cancer (FIRE-3): a randomised, open-label, phase 3 trial. Lancet Oncol 2014;15:1065-1075. 169. Yoshino T, Portnoy DC, Obermannová R, et al. Biomarker analysis beyond angiogenesis: RAS/RAF mutation status, tumour sidedness, and second-line ramucirumab efficacy in patients with metastatic colorectal carcinoma from RAISE-a global phase III study. Ann Oncol 2019;30:124-131.

170. Rodriguez-Pascual J, Cubillo A. Dynamic Biomarkers of Response to Antiangiogenic Therapies in Colorectal Cancer: A Review. Curr Pharmacogenomics Person Med 2017; $15: 81-85$.

171. Pratyaksha Wirapati. Velour trial biomarkers update: Impact of RAS, BRAF, and sidedness on aflibercept activity. JOURNAL OF CLINICAL ONCOLOGY 2017;35:35383538.

172. Tabernero J, Yoshino T, Cohn AL, et al. Ramucirumab versus placebo in combination with second-line FOLFIRI in patients with metastatic colorectal carcinoma that progressed during or after first-line therapy with bevacizumab, oxaliplatin, and a fluoropyrimidine (RAISE): a randomised, double-blind, multicentre, phase 3 study. The Lancet Oncology 2015;16:499-508.

173. Teufel M TS. Molecular subtypes and outcomes in regorafenib-treated patients with metastatic colorectal cancer (mCRC) enrolled in the CORRECT trial. J Clin On 2015;33:3358-3558.

174. Weekes C, Lockhart AC, Lee JJ, et al. A phase $1 \mathrm{~b}$ study evaluating the safety and 
pharmacokinetics of regorafenib in combination with cetuximab in patients with advanced solid tumors. Int J Cancer 2019.

175. Vogel A, Hofheinz RD, Kubicka S, et al. Treatment decisions in metastatic colorectal cancer - Beyond first and second line combination therapies. Cancer Treat Rev 2017;59:5460.

\section{Figure legends}

\section{Figure 1. The Microenvironment of Colorectal Tumors}

Dispersed immune cells are in the tumor center, mostly in the invasive margin that juxtaposes the non-tumor area of the colon, with some forming TLS. Blood vessels, high endothelial venules, and lymphatic vessels allow entry and/or egress of immune cells.

\section{Figure 2. The Consensus Molecular Subtypes}

CMS1 and CMS4 tumors are highly infiltrated by immune cells, whereas CMS1 tumors are characterized by a Th1-cell response and activated and inflamed TME. These tumors can be treated with immune checkpoint inhibitors. CMS4 tumors have an inflamed, complementrich, suppressive and highly angiogenic TME that can be targeted with combination therapies. CMS2 do not activate an anti-tumor immune response, due to activation of the beta-catenin pathway, and CMS3 considered to be metabolic tumors.

\section{Figure 3. Treatment of MSI and MSS Tumors}

MSI tumors should be treated with immune checkpoint inhibitors, specifically with inhibitors of PD1, potentially combined with inhibitors of CTLA4. Among MSS tumors, patients with tumors without mutations in RAS respond to cetuximab or panitumumab in combination with chemotherapy. Tumors with mutations in APC and activation of WNT signaling to betacatenin might be treated with inhibitors of beta-catenin or PAX4. Mesenchymal-type tumors might be treated with a combination of immune checkpoint inhibitors and anti-angiogenic, anti-inflammatory, anti-complement, or anti-TGFB agents, in combination with chemotherapy. RAS mutant tumors might respond to anti-angiogenic therapies, T-cell-based, or T-cell activating immunotherapies. 